\title{
La Organización de los Estados Americanos y su labor en pro de la democracia en las Américas*
}

\author{
Hugo de Zela Martínez
}

La historia de la Organización de los Estados Americanos refleja la de sus Estados miembros y la lucha que han librado a lo largo de sesenta y cuatro años para equilibrar el principio de no intervención, con algunas excepciones en nombre de la democracia y los derechos humanos. Con decisiones basadas en el consenso, esa lucha se centra ahora en hallar los medios más adecuados para aplicar la Carta Democrática Interamericana, adoptada el año 2001.

Desde las gestas libertadoras en América del Sur, pasando por las luchas para lograr la independencia en Centroamérica, hasta las guerras por la finalización del dominio colonial en Estados Unidos, la noción de democracia ha estado permanentemente presente en las aspiraciones de los pueblos americanos. No es por ello extraño que, cuando sus representantes decidieron fundar en 1948 - como sucesora de la Unión Panamericana - la Organización de los Estados Americanos (OEA), incluyeran en su carta fundacional una mención a que su solidaridad requiere "la organización política de los mismos sobre la base del ejercicio efectivo de la democracia representativa", como dice el actual artículo 3 de la citada carta.

* El autor desea expresar su agradecimiento a Pamela Moraga por su colaboración en este artículo. 
Sin embargo, esa aspiración, ese objetivo, ha enfrentado una serie de altibajos a través de la historia regional desde ese importante momento. En el presente artículo paso revista a las seis décadas y media transcurridas desde el momento de la adopción de la Carta de la Organización de los Estados Americanos hasta la actualidad. Mi objetivo consiste no solo en evocar hechos históricos, sino también en reflexionar sobre las circunstancias que promueven el avance de la democracia, los mecanismos establecidos para defenderla y las dificultades que enfrentamos en el mundo real cuando esta se ve amenazada.

A lo largo de este artículo centraré la atención en la evolución del concepto de "democracia" en el hemisferio y las distintas circunstancias en que la acción colectiva de los países miembros de la OEA se ha ejercido, fundamentalmente, para su defensa.

\section{Los primeros veinte años}

Finalizada la Segunda Guerra Mundial, Truman y Eisenhower se encontraron con un mundo diferente, en el cual debían convivir con una situación de frecuente tensión entre dos visiones opuestas del mundo y la permanente preocupación de que la Unión Soviética y sus aliados incrementaran su influencia en las Américas. Por ello, concluyeron que una de las principales responsabilidades de Estados Unidos era proteger de la expansión comunista a los países americanos, objetivo en procura del cual apoyaron grupos que perseguían aplastar movimientos revolucionarios considerados de inspiración comunista. Ello significó, con frecuencia, intervenciones en diversos países de la región, e incluso su invasión, todo ello en nombre de la defensa de la democracia.

En ese contexto regional, en 1948, veintiún países adoptaron la Carta de la Organización de los Estados Americanos. Es interesante destacar que uno de los principios básicos de esa carta fue el de la no intervención en los asuntos internos de los Estados miembros. Paradójicamente, la inclusión de este principio puede tener una doble lectura: la primera, el deseo de limitar la posibilidad de que Estados Unidos interviniera en los asuntos internos de esos Estados; la segunda, que ese principio no era más que otro mecanismo respaldado por Estados Unidos para la lucha contra la expansión comunista, pues cualquier acción de un país comunista para impulsar sus intereses podía ser considerada intervención en asuntos internos de un país miembro y, por lo tanto, sujeta a la defensa colectiva en aplicación de la Carta de la OEA. Pero el elemento 
común es que, ideológicamente, se asumía que los países americanos fundadores de la OEA estaban organizados - como lo afirmaron en su carta- sobre la base de la democracia y su defensa, y, por ello, se contraponían a aquellos otros Estados cuyos sistemas políticos eran "no democráticos". Así, la OEA en varios casos aceptó golpes de Estado porque, supuestamente, al defender al país del avance del comunismo fortalecían la democracia. Hubo varios ejemplos de ello en América del Sur y América Central.

Como parte de esa lucha contra el comunismo, el sistema interamericano se utilizó también para crear un marco de seguridad regional encaminado a poner freno a la expansión de ideologías totalitarias y, al mismo tiempo, respaldar el intervencionismo estadounidense. Así surgieron doctrinas de "seguridad nacional", junto con instrumentos y órganos destinados a difundirlas en el hemisferio: el Tratado Interamericano de Asistencia Recíproca" (comúnmente conocido como "Tratado de Río"), la Junta Interamericana de Defensa, fundada ya en 1942, y, en especial, el Colegio Interamericano de Defensa (1962). Ello significó que no solo se contaba con un marco político, sino que existía también un marco militar para la rápida adopción de medidas en cada caso en que fueran necesarias. La promulgación en Estados Unidos de la Ley de Asistencia Recíproca ${ }^{2}$, en 1951, reforzó esos dispositivos al autorizar la entrega de asistencia económica, técnica y militar a países amigos para fortalecer la seguridad y el "Mundo Libre". Según el Segundo Informe dirigido al Congreso por la Agencia de Asistencia Recíproca de Estados Unidos, en 1952, el monto de la asistencia militar directa proporcionada a la región alcanzó un total de USD 38.2 millones $^{3}$. En la década de los cincuenta, Estados Unidos suscribió acuerdos de asistencia recíproca en materia de defensa con dieciséis países latinoamericanos: Ecuador, Cuba, Colombia, Perú y Chile (1952); Brasil, República Dominicana y Uruguay (1953); Nicaragua y Honduras (1954); Guatemala y Haití (1955); Bolivia (1958); El Salvador, Panamá y Costa Rica (1962); y Argen-

1 Tratado Interamericano de Asistencia Recíproca: <http://www.oas.org/juridico/ english/treaties/b-29.html>.

2 Ley de Seguridad Mutua de 1951, US Public Law 165, 10 de agosto de 1951.

3 Segundo informe al Congreso sobre el Programa de Seguridad Mutua, Agencia de Seguridad Mutua de Estados Unidos, 1952. Recuperado de http://archive. org/details/reporttocongress1952unit 
tina (1964), adquiriendo así aliados formalmente comprometidos a esforzarse en combatir la expansión del comunismo.

\section{Los años setenta}

Es recién en los años setenta que esta construcción teórico-política que privilegiaba la comprensión del concepto de democracia - como el régimen opuesto al comunismo, justificando, incluso, golpes de Estadoempieza a modificarse. $\mathrm{Y}$ lo hace principalmente porque varias de las dictaduras de los años sesenta y comienzos de los setenta, especialmente en América del Sur, empiezan a debilitarse y finalmente a caer. En forma paralela, se produce en Estados Unidos, sobre todo bajo la presidencia de Jimmy Carter, una muy fuerte defensa de los derechos humanos. En ese contexto, el principio de no intervención se relativizó; se empieza a aceptar que, en nombre de la defensa de los derechos humanos, es legítimo adoptar decisiones más allá de la esfera de competencia nacional y protegerlos donde quiera que fueran violados. Esto ocurría, precisamente, en el periodo en que surgieron en Sudamérica los primeros movimientos encaminados a restaurar la democracia. No obstante, al mismo tiempo, en los países centroamericanos surgieron conflictos internos, suscitados sobre todo por la continua pugna de las potencias por el predominio geopolítico mundial.

Muy poco antes de iniciarse la década de los setenta, en noviembre de 1969, ocurre un hecho trascendente: se firma la Convención Americana de Derechos Humanos, mediante la cual los Estados parte codifican y se obligan a defender una serie de derechos y, además, dan fuerza convencional a la actuación de la Comisión y de la Corte Interamericana de Derechos Humanos, consagrando jurídicamente la tesis de que la defensa de esos derechos hace legítima la acción colectiva y que hacerlo no es una violación del principio de no intervención.

Ese fue el comienzo de una tendencia regional en que la defensa colectiva de los derechos humanos empezó a ser considerada como un tema legítimo en la agenda hemisférica. La Comisión Interamericana de Derechos Humanos comienza a hacer informes sobre la situación de derechos humanos en determinados países, visitas in situ, denuncias públicas de violaciones a los derechos humanos, y a enfrentar a los gobiernos que sostenían que sus acciones eran de intervención en asuntos internos de los países. Ello dio lugar a la movilización de organizaciones de la sociedad civil en respaldo de la labor de la comisión, lo que 
a su vez le permitiría a esta ampliar gradualmente sus operaciones, hasta el punto de que sus quejas empezaron a resonar en el exterior.

\section{La década de los ochenta}

Pese a esos acontecimientos y tendencias, recién a fines de la década de los ochenta se dio en la región un renovado impulso a la defensa y promoción de la democracia. Se produce, allí, la segunda etapa de relativización del principio de no intervención. Esto se origina por la coincidencia de varios hechos:

- El fin de algunas dictaduras en la región y el comienzo de una tendencia hacia la consolidación democrática, en especial en América del Sur.

- El conflicto interno en América Central y su intensificación.

- El efecto de la intervención de Estados Unidos en la guerra que se libraba en América Central, que dio lugar a una confrontación entre el Poder Ejecutivo y el Congreso.

El conflicto de América Central - uno de los más sangrientos que ha tenido lugar en la región - es un ejemplo elocuente de las contradicciones generadas por los acontecimientos suscitados en la región. Se dio en países que se veían enfrentados a circunstancias internas devastadoras, en medio de una pobreza endémica, de violencia militar y paramilitar y de insurrecciones armadas tan graves que se utilizaron como pretexto para justificar el intervencionismo estadounidense durante el gobierno de Reagan, principalmente en Nicaragua. Tras el triunfo de la revolución, en julio de 1979, Estados Unidos organizó y financió la "resistencia nicaragüense", conocida como la de los "Contras".

Se afirma que el monto del financiamiento "oficial" otorgado por el Gobierno de Estados Unidos a los "Contras" entre 1981 y 1988 ascendió aproximadamente a USD 278.85 millones. Con el tiempo, ese gasto de recursos y la subsiguiente decisión de Estados Unidos de intervenir directamente en la guerra en América Central suscitaron una viva controversia en la sociedad estadounidense, en especial cuando estalló el escándalo "Irán-Contras".

La intervención de Estados Unidos en defensa de la democracia y del "Mundo Libre" causó varios desequilibrios en las relaciones regionales, al introducir abiertamente en la región la pugna ideológica. 
La exacerbación y regionalización del conflicto en América Central y la consiguiente comprensión, por los países centroamericanos, de que el conflicto podía expandirse, dieron lugar a una reacción latinoamericana encaminada, entre otros objetivos, a contener los intereses intervencionistas de Estados Unidos. En 1983, México, Colombia, Venezuela y Panamá convocaron y pusieron en marcha el Proceso de Contadora. En 1985, otros cuatro países sudamericanos - Argentina, Brasil, Uruguay y Perú - se unieron a lo que pasó a llamarse el Grupo de Apoyo. El proceso, encabezado por los mencionados países, tuvo sus altibajos, pero logró sembrar la idea de que era esencial poner límite a la intervención de Estados Unidos y procurar soluciones no armadas al cruento conflicto que estaba teniendo lugar en América Central. Mientras se desarrollaba ese proceso, Estados Unidos bloqueó toda iniciativa de la OEA que pudiera reducir su margen de maniobra. A la larga, ni el Proceso de Contadora ni su Grupo de Apoyo lograron generar una opción viable para una paz duradera.

No obstante, esas primeras acciones latinoamericanas conjuntas iniciaron un largo proceso de unidad y voluntad política que, con el tiempo, aumentó significativamente la presencia e influencia de América Latina en los asuntos regionales. Así, el Proceso de Contadora y su Grupo de Apoyo evolucionaron hasta dar lugar al Grupo de Río y a lo que ahora se conoce como Comunidad de Estados Latinoamericanos y Caribeños (Celac).

En una nueva fase, y con sólido respaldo latinoamericano, surgió una segunda iniciativa multilateral dentro de los países desgarrados por conflictos, consistente en la primera Cumbre Presidencial Centroamericana, conocida como Esquipulas I, que se celebró en mayo de 1986 para evaluar la situación centroamericana y el estado del Proceso de Contadora. La cumbre restableció el diálogo entre los países centroamericanos y adoptó la Declaración de Esquipulas I, donde se acordó formalizar reuniones presidenciales y reiterar la disposición de las autoridades de suscribir el Acta de Contadora para la Paz y Cooperación en Centroamérica. No obstante, una vez más, esos tan esperados resultados no se materializaron. A principios de 1987, América Central atravesaba una situación muy difícil. Tras agotar las opciones de negociación, Óscar Arias, presidente de Costa Rica, organizó una Cumbre de Presidentes Centroamericanos (de la que Nicaragua fue excluida), que se celebró el 15 de febrero de 1987 en San José. En esa cumbre, Arias presentó lo que 
llegó a conocerse como el "Plan Arias", como base para las negociaciones que culminaron el 7 de agosto de 1987, con la firma, en Esquipulas, del documento titulado "Procedimiento para establecer la paz firme y duradera en Centroamérica" (Esquipulas II). Ese proceso avanzó hasta que, en 1989, los presidentes centroamericanos decidieron recurrir a la asistencia conjunta de la OEA y de las Naciones Unidas, que, en una acción sin precedentes, unieron fuerzas para proporcionar el respaldo necesario para llevar por fin a esa iniciativa a una conclusión exitosa. La contribución de la OEA se materializó principalmente en Nicaragua a través del establecimiento de la Comisión Internacional de Apoyo y Verificación (CIAV), establecida para verificar el desarme de los Contras, y a través de la observación de las elecciones generales que culminaron con la victoria de Violeta Chamorro y la salida de los sandinistas del poder. Estados Unidos se opuso con vehemencia a la intervención de la OEA, pero los países latinoamericanos respaldaron categóricamente la posición de esta organización.

Una importante consecuencia de este proceso fue la modificación de la manera en que Estados Unidos y los países latinoamericanos habían de interactuar frente a las crisis regionales. El nuevo enfoque se basaba en la convicción de que el intervencionismo estaba en declive y que, al mismo tiempo, la defensa de la democracia y los derechos humanos constituía una legitima excepción al principio de la no intervención. Este cambio, y especialmente la experiencia que la OEA había extraído del proceso de paz centroamericano, se ven reflejados en los instrumentos jurídicos de la organización. Hubo entonces modificaciones a la Carta de la Organización y se acordaron importantes resoluciones sobre la democracia.

No obstante, para ver estos hechos en su debido contexto, vale la pena recordar algunos intentos anteriores tendientes a hacer referencias colectivas a la democracia. Como se señaló párrafos atrás, en la Carta de 1948 hubo una mención a ella y, luego, la Declaración de Santiago de 1959 enunciaba los atributos de la "democracia representativa". Pero, a pesar de estas claras referencias, es interesante destacar que en ninguno de los dos casos se daba alguna competencia o mandato a la OEA para actuar en defensa de la democracia, pues la vigencia del principio de no intervención seguía siendo defendida por la mayor parte de sus países miembros.

Recién en 1985, con el Protocolo de Cartagena de Indias4, se incluyó, entre los objetivos esenciales de la OEA, la promoción y consolidación de la democracia representativa con el debido respeto al principio de no 
intervención. Además, el artículo 110 de la Carta de la organización confirió a su secretario general la potestad de poner a consideración del Consejo Permanente de la OEA problemas que pudieran afectar la paz y la seguridad o el desarrollo en los Estados miembros. Este es un cambio fundamental en la organización, pues se decidía que la democracia representativa pasaba a ser una de las razones de existir de la OEA al consagrarla como uno de sus propósitos esenciales. Ello se complementa con las nuevas atribuciones otorgadas al secretario general. Este cambio tiene un significado político importante, pues el máximo representante de la organización deja de ser concebido fundamentalmente como un administrador de la institución, para pasar a ser un actor, con capacidad de iniciativa, en temas de importancia central para los países miembros. Esta reforma a la Carta fundacional convirtió el ya relativizado principio de no intervención en un principio ahora definitivamente "matizado".

Poco tiempo después, ya a fines de los ochenta, precisamente en 1989, y estando la idea de promover y consolidar la democracia aún fresca en sus mentes, los Estados miembros adoptaron la resolución "Derechos Humanos y Democracia-Observación Electoral", que entregó al secretario general de la OEA el mandato de llevar a cabo misiones de observación electoral regulares, a solicitud del país donde fuera a ocurrir el acto electoral, pues se consideraba que las democracias debían contar con una legitimidad de origen mediante la realización de elecciones libres, justas, respetando las reglas establecidas y con una presencia internacional. El principio de no intervención continuaba siendo relativizado.

\section{Los años noventa}

Es precisamente en aplicación de esa resolución y de la nueva etapa que se empieza a vivir en la OEA, que se organiza la primera de sus observaciones electorales modernas. Esta operación - que duró cuatro meses y empleó a casi cuatrocientas personas - tuvo lugar en Nicaragua, en 1990, y fue la primera de muchas otras que luego se han desarrollado en casi todos los países de la región y que constituyen una de las actividades más destacadas y reconocidas de la organización.

4 Protocolo de Enmienda de la Carta de la Organización de los Estados Americanos (A-50), "Protocolo de Cartagena de Indias". Recuperado de http://www.oas. org/dil/treaties_A-50_Protocol_of_Cartagena_de_Indias_sign.htm 
Poco después, también en 1990, se crea en la Secretaría General de la OEA la "Unidad para la promoción de la Democracia", que tuvo a su cargo el desarrollo de las nuevas responsabilidades que asumía el organismo hemisférico. A la unidad se le encomendó la elaboración de políticas a mediano y largo plazo sobre la promoción y consolidación de instituciones democráticas. En 1991, la Declaración de Santiago5 ("Compromiso de Santiago con la Democracia") renovó el apoyo para la democracia y sentó las bases para un acuerdo en gran escala entre los países para ocuparse de la protección del sistema democrático: Resolución AG/RES. 1080 (XX1-O/91), "Democracia representativa"6, donde por primera vez se incorporaron mecanismos de sanciones para los casos de abrupta o irregular interrupción del proceso político institucional democrático. Ello fue complementado por el Protocolo de Washington de 19927, que enmendó la Carta de la Organización de los Estados Americanos para hacer posible la adopción de medidas colectivas tendientes a expulsar de la OEA a un país cuyo gobierno hubiera sido derrocado por la fuerza. Estos cambios son una clara demostración de la voluntad coincidente de los países americanos de promover la democracia y, en caso necesario, de actuar colectivamente para restaurarla cuando se hubiera visto afectada. Se consolida así, jurídica y políticamente, la tendencia de crear una segunda excepción al principio de no intervención, en nombre de la defensa de la democracia.

Hay algunos factores que vale la pena destacar para entender por qué fue posible que esta evolución se produjera. En primer lugar, el "efecto comprobado" de la Comisión Interamericana de Derechos Humanos, cuya labor, durante más de una década, de defensa de los derechos humanos en la región, había probado de manera fehaciente el hecho de que la acción colectiva puede, sin lugar a dudas, suscitar un impacto positivo. En segundo lugar, un cambio importante en la ecuación política fue el ingreso de Canadá en la OEA, en 1990. Canadá trajo consigo una larga tradición democrática que significó en la organiza-

5 “Compromiso de Santiago para la democracia y la renovación del sistema interamericano". Tercera sesión plenaria de la Asamblea General, 4 de junio de 1991. Recuperado de http://scm.oas.org/pdfs/agres/ag03805E01.pdf

6 Resolución AG/RES. 1080 (XXI-O/91), “Democracia representativa”. Recuperado de http://www.oas.org/juridico/english/ agres1080.htm

7 Protocolo de Enmiendas a la Carta de la Organización de los Estados Americanos (A-56), "Protocolo de Washington". Recuperado de http://www.oas.org/dil/ treaties_A-56_Protocol_of_Washington.htm 
ción un muy fuerte impulso por fortalecer la acción colectiva en temas de democracia. En tercer lugar, en esa etapa se produjeron algunas crisis que pusieron a prueba los principios y compromisos recién adoptados. Frente a estas situaciones, se demandó una reacción del organismo regional, precisamente sobre la base de los nuevos acuerdos.

Fue entonces que, en efecto, la OEA tuvo una activa intervención en varios casos de interrupción de los procesos democráticos ocurridos en la época. Así ocurrió en Haití (1991), Perú (1992), Guatemala (1993) y Paraguay (1996). En todos esos casos se aplicaron los mecanismos acordados mediante la antes citada Resolución AG/RES 1080.

En todas esas crisis la OEA cumplió un importante papel, ejerciendo genuina influencia en el hemisferio, específicamente en la denominada "ola de democratización en la región". Pero, como en todos los procesos llevados a cabo en los organismos internacionales, ha habido retrocesos. Estos importantes actos de defensa colectiva de la democracia develaron algunos vacíos y, sobre todo, demostraron que los compromisos colectivos aún eran insuficientes. A ello contribuyó, en grado importante, lo ocurrido en el Perú a mediados de los años noventa. Poco antes, en 1992, el Congreso y el Poder Judicial habían sido declarados disueltos por el Poder Ejecutivo, con lo que se dio inicio a una seria crisis política. Allí se produjo una intervención de la OEA, que culminó un año después con el llamado a elecciones para la Asamblea Constituyente que aprobó una nueva Constitución, la cual permitió una primera reelección del presidente Fujimori. Sin embargo, en el año 2000, Fujimori busco justificar una segunda reelección a través de una interpretación, de la Constitución, mayoritariamente rechazada interna e internacionalmente. Se realizaron elecciones, observadas por la OEA, y la misión electoral declaró que no se habían realizado conforme a los estándares internacionales. Se produjo una nueva intervención de la OEA, que promovió un dialogo nacional y, finalmente, como resultado de ese proceso, el presidente renunció a su cargo.

Esa participación fue un punto de inflexión, pues dio lugar a la idea de que no basta, para prevenir amenazas a los sistemas democráticos, asumir compromisos.

Se habían creado mecanismos basados en la percepción generalizada de que las amenazas a dichos sistemas solo provienen de golpes militares, sin tener en cuenta otros tipos de peligros, como el surgimiento de regímenes "formalmente democráticos", producto de elec- 
ciones populares, que se tornan autoritarios debido a debilidades institucionales. La reacción ante esos tipos de regímenes dio lugar a que el principio de la no intervención, que todavía parecía jugar algún papel en las decisiones de los países miembros en el Consejo Permanente, fuera visto como un factor negativo que debía reinterpretarse a la luz de los acontecimientos. Algunos casos, como el de Guatemala en 1993, con la disolución del Parlamento y la clausura de la Corte Suprema de Justicia ordenada por un presidente democráticamente electo, dejaron en claro que se insinuaban nuevos peligros que amenazaban a las democracias de la región y que los instrumentos disponibles eran demasiado insuficientes para enfrentar los nuevos desafíos.

\section{La primera década del siglo XXI}

Esa creciente determinación colectiva de fortalecer las disposiciones democráticas se expresó oficialmente en la Cumbre de las Américas celebrada en la ciudad de Quebec, Canadá, en $2001^{8}$, ocasión en que se estableció la "Cláusula Democrática" y tomó forma la idea de redactar una carta sobre democracia en la región, encargándose a los cancilleres de los países miembros adoptar una en su siguiente sesión.

Esa Carta Democrática Interamericana ${ }^{9}$ fue aprobada en periodo extraordinario de sesiones de la Asamblea General celebrada el 11 de setiembre de 2001 en Lima, Perú.

Esta carta:

- Hace referencia a todos los elementos que debe tener un gobierno democrático y, además, consigna los compromisos de los países miembros para defender ese modo de vida si es que llega a verse afectado. En este sentido, constituye una especie de programa de gobierno para una república democrática.

- Constituye un ejemplo de la voluntad política pragmática, no ideológica, de profundizar los principios democráticos y actuar en consonancia con ellos.

8 Declaración de Quebec, Oficina de Seguimiento de Cumbres de la OEA, 3 Documentos oficiales emanados de las Cumbres de las Américas, Proceso comprendido entre Miami y la ciudad de Quebec 313 (2002). Recuperado de http:// www.summit-americas.org

9 Carta Democrática Interamericana. Recuperado de http://www.oas.org/charter/ docs/resolution1_en_p4.htm 
- Recopila sistemáticamente conceptos anteriormente enunciados en diversos instrumentos y, al mismo tiempo, introduce nuevos conceptos, como el "derecho a la democracia" de los pueblos de las Américas; la obligación de sus gobiernos de promover y defender la democracia; la definición de los elementos esenciales de la democracia representativa y el vínculo expreso entre democracia y respeto y promoción de los derechos humanos, entre otras cosas.

- En ese contexto, establece la "defensa de la democracia" como una segunda excepción (la defensa de los derechos humanos es la primera) a la aplicación irrestricta del principio de no intervención.

La Carta Democrática no se limita a los puntos indicados, sino que además establece medidas y decisiones específicas que han de adoptar los Estados miembros en determinada situación que pueda afectar al orden democrático. Esas medidas abarcan visitas al país de que se trate, para analizar la situación; informes al Consejo Permanente; buenos oficios; iniciativas diplomáticas e incluso la suspensión del derecho de un Estado miembro de participar en la OEA.

En los once años de existencia de la Carta Democrática Interamericana, ha sido invocada en nueve ocasiones: en Venezuela en 2002-2004, en Nicaragua en 2005, en Ecuador en 2005, en Bolivia en 2008, en Guatemala en 2009, en Paraguay en 2009, en Honduras en 2009-2010, en Ecuador en 2010, y en Haití en 2010-2011.

De esos nueve casos, los de Venezuela (2002) y Honduras (2009) se consideraron perturbaciones del orden democrático, y en los siete restantes la Carta Democrática se aplicó de manera preventiva para evitar el agravamiento de crisis políticas e institucionales que pudieran haber comprometido la continuidad del proceso democrático.

En Venezuela, en 2002, el presidente fue derrocado y detenido por fuerzas militares, y el jefe de Estado de facto anunció la disolución del Congreso y del Poder Judicial. El Consejo Permanente se reunió de inmediato y, en aplicación del artículo 20 de la Carta Democrática Interamericana, determinó el envío de una misión encabezada por el secretario general para investigar los hechos y realizar gestiones diplomáticas a fin de procurar la pronta normalización de la situación. El secretario general realizó la misión e informó luego a una sesión de la Asamblea General. La crisis se solucionó pocos días después, con el retorno del presidente al poder. 
En Honduras, en 2009, se produjo un golpe de Estado y se destituyó por la fuerza al presidente. De inmediato, el Consejo Permanente encargó gestiones al secretario general y convocó a un periodo extraordinario de la Asamblea General, la que condenó el golpe. El secretario general continuó sus esfuerzos encaminados a reestablecer la democracia, pero sus gestiones no produjeron la vuelta a la normalidad, de lo que informó a la Asamblea General. Esta, en consecuencia, decidió suspender a Honduras, en aplicación del artículo 21 de la Carta Democrática Interamericana, del ejercicio de su derecho de participación en la OEA y encomendó que se intensificaran las gestiones para la restauración de la normalidad democrática.

Se enviaron varias misiones al país, para realizar gestiones de diverso tipo. Finalmente, hubo elecciones que permitieron que un nuevo gobierno asumiera el poder, y tiempo después, casi dos años más tarde de su imposición, se levantó la suspensión de Honduras, en junio de 2011, con lo cual volvió a tener representación en la organización.

Al considerar el tema de la aplicación de la Carta Democrática, es inevitable referirse al debate referente a Cuba llevado a cabo en el seno de la organización.

En 2009, se trata en la OEA - después de casi cincuenta años - el caso de la suspensión de Cuba, aprobada en 1962. Como se recordará, en pleno enfrentamiento contra el comunismo, se decidió en una reunión de consulta de cancilleres excluir al Gobierno de Cuba de su participación en el Sistema Interamericano. Ello se debió a que, según se afirmó, Cuba había adherido al "marxismo-leninismo," estaba alineada con el bloque comunista y había desarrollado acciones incompatibles con los principios y propósitos de la Carta de la OEA.

El texto de la resolución fue, claramente, una demostración del peso de Estados Unidos en el ente hemisférico en ese entonces.

Pero, años después, ya casi al final de la primera década del siguiente siglo, mucho había cambiado en la OEA y una amplia mayoría de los Estados miembros había dejado de apoyar el aislamiento cubano. El tema se planteó tiempo antes, a nivel del Consejo Permanente y en una reunión de cancilleres realizada en San Pedro de Sula, Honduras, en 2009, durante la Asamblea General ordinaria de ese año. El tema dominó las deliberaciones. Hubo una férrea oposición norteamericana y de unos pocos países más, pero al final la mayoría se impuso y se aprobó dejar sin efecto la resolución de 1962, con lo que el impedimento para 
que Cuba retornara a la OEA cesó de tener vigencia. Sin embargo, ese retorno al seno de la organización no se concibió en términos automáticos: mucho había sucedido en la OEA, entre tanto, incluida la adopción de la Carta Democrática. Por ello, la resolución respectiva contiene un segundo párrafo que sostiene que la participación del Gobierno de Cuba será el resultado de un proceso de diálogo iniciado a su solicitud y de conformidad con las prácticas, propósitos y principios de la OEA, incluida ahora, obviamente, la Carta Democrática.

Desde entonces, la reintegración de Cuba al sistema interamericano ha sido motivo de continuos debates. En 2012, en medio de la organización de la Sexta Cumbre de las Américas, en Cartagena de Indias, Colombia, la cuestión fue planteada una vez más. Los resultados de las consultas celebradas en esa ocasión con respecto a la participación de Cuba irán viéndose a medida que se acerque la fecha de la próxima cumbre, que se celebrará en Panamá en 2015.

\section{La segunda década de $\mathbf{2 0 0 0}$}

Los Estados miembros de la OEA aprovecharon en 2011 la oportunidad ofrecida por el décimo aniversario de la aprobación de la Carta Democrática Interamericana para realizar una evaluación crítica de la manera en que esta se ha aplicado. El resultado más claro de este interesante proceso de evaluación fue la constatación de que el panorama político de la región ha cambiado y que se está poniendo en tela de juicio el consenso que había gestado la Carta Democrática Interamericana.

El Consejo Permanente emitió un informe final sobre dicho diálogo. Entre las principales conclusiones consignadas en dicho informe, destacan las siguientes:

a) Se decidió mantener el texto de la Carta Democrática sin modificaciones.

b) Se consideró que la tarea debía concentrarse en buscar vías y mecanismos para mejorar la aplicación y la efectividad de la Carta Democrática.

c) Se resaltó el enfoque integral de la democracia que contiene la Carta Democrática.

d) Se decidió acelerar la aprobación de la Carta Social, como un complemento de la Carta Democrática. 
e) Se consignaron varias propuestas específicas sobre prevención y promoción de la democracia, para evitar el peligro de una ruptura de la institucionalidad, aunque no hubo acuerdo sobre ninguna de ellas.

Esta falta de consenso en el Consejo Permanente es sintomática: constituye un reflejo de que hoy existen en la región puntos de vista diferentes sobre los conceptos que la Carta Democrática Interamericana contiene. Por ello, es interesante hacer un breve análisis de lo que ocurre. Los Estados miembros han alcanzado formalmente un consenso en torno a principios democráticos tradicionales, en especial en cuanto al origen de su legitimidad: el acceso al poder a través de elecciones populares, que son, por naturaleza, competitivas y pluripartidarias.

El "ejercicio de la gobernanza" dentro de los Estados es el ámbito en que comienzan a aparecer nuevos conceptos. Ha surgido una nueva definición de la democracia, acuñada como "democracia participativa" por los países del ALBA, tendiente a cambiar e impugnar el paradigma de la "democracia representativa".

En forma paralela, un fenómeno que viene dándose con frecuencia es que la figura del presidente, del jefe de Estado, cuyo carisma, energía y personalidad se proyectan con mucha fuerza, tiene una influencia decisiva en la vida del país. Ese poder ejecutivo fuerte, que con frecuencia procura mantenerse en el poder a través de reelecciones, puede ocasionar que las instituciones democráticas se debiliten y que no haya los necesarios contrapesos al no existir una clara división de poderes públicos y ámbitos de competencia administrativa.

Algunos países de la región han dado muestras de una tendencia a abandonar el consenso que otrora diera origen a los compromisos asumidos en la Carta Democrática Interamericana o por lo menos en cuanto a la forma en que dicho instrumento debe aplicarse. En consecuencia, los Estados miembros están divididos en lo que respecta a lo que es la democracia, cuáles son sus elementos definitorios y cómo debe defenderse.

Estas diferencias ideológicas tienen una consecuencia práctica porque, en el modus operandi de la organización, el mecanismo de adopción de decisiones que prefiere es la búsqueda del consenso. Ello es especialmente problemático cuando se trata de aplicar la Carta Democrática, pues muchas veces no es posible llegar a una decisión y se produce una especie de parálisis institucional que torna mucho más compleja la adopción de medidas, por lo que la acción de la organización se paraliza o se hace también muy compleja. 
En términos prácticos, lo anterior permite concluir que existe la necesidad de una mayor claridad de ideas, de aclaraciones adicionales sobre las normas existentes y de la introducción de mecanismos para dar respuesta a nuevas amenazas a la democracia, complementando los que ya contiene la Carta Democrática.

El efecto paralizante de la ideología sobre el consenso, especialmente en cuanto atañe a la aplicación de la Carta Democrática, ha sido especialmente evidente en los debates del Consejo Permanente sobre las crisis más recientes ocurridas en la región, en Honduras (2009) y Paraguay (2012). En cada uno de esos casos, las posiciones están alineadas más en función de la ideología que de la aplicación de los principios de la Carta Democrática Interamericana.

Un atributo común del panorama regional ideológicamente dividido es la percepción generalizada - en algunos ámbitos - de que la organización es inerte, de que no funciona, de que es un instrumento del imperialismo estadounidense, que lo mejor sería acudir a otros organismos regionales. No obstante, si se examinan con más detenimiento las disposiciones relacionadas con la democracia existente en esas entidades, sus "cláusulas democráticas", todas ellas dicen que cualquier ataque al Poder Ejecutivo es una alteración del proceso democrático. Nada se dice acerca de lo que ocurre cuando surgen otros tipos de problemas o amenazas.

\section{7. ¿Qué se puede hacer en la OEA?}

Teniendo presente esa situación, ¿qué debería hacerse en la OEA?, y, más específicamente, ¿qué debería hacerse con la Carta Democrática en el clima político regional actual?

1. En primer lugar, valdría la pena concentrar esfuerzos en lograr una definición más clara y precisa de los conceptos utilizados en la Carta Democrática, como "alteración del orden constitucional" o "grave afectación del orden democrático." Cada vez que se presenta un caso específico, la falta de definiciones colectivamente aceptadas dificulta la acción del organismo. Una definición adoptada por anticipado, sin referencia a algún caso específico, facilitaría la capacidad de reacción de la OEA cuando llega el momento de actuar.

2. Como concluyeron los propios Estados miembros en su evaluación de los diez primeros años de la Carta Democrática, "es 
mejor prevenir que curar". Por lo tanto, un área de trabajo de gran importancia es la de lograr posibilidades de adopción de medidas preventivas conforme a la Carta Democrática. Esta tarea no debe verse solamente desde un ángulo negativo, esto es, la prevención de problemas; deberían considerarse también acciones de promoción y de educación democráticas que fortalezcan la institucionalidad y hagan menos factible su alteración o interrupción. Ambos aspectos están claramente mencionados en la Carta Democrática, por lo que el acuerdo político en lo que se refiere a sus alcances ya existe.

3. Es evidente que, dentro de la organización, el órgano apropiado para desarrollar las tareas de prevención orientadas a poner en práctica un mecanismo de alerta temprana que permita actuar con la anticipación suficiente con el fin de evitar alteraciones del orden democrático es la Secretaría General. Por lo tanto, los mecanismos de seguimiento de ese órgano requieren precisiones y cometidos específicos.

Si se pudiera avanzar en esas tres áreas, se estarían dando pasos prácticos y efectivos para mejorar la efectividad de la aplicación de la Carta Democrática Interamericana e incrementar la capacidad de respuesta de la OEA. Pero ello solo es posible si actuamos juntos.

Creemos que se puede afirmar que la OEA ha sido y sigue siendo pertinente en el hemisferio. No obstante, sería ingenuo pensar que la organización ha sido inmune a las divisiones ideológicas de la región. Creemos que también es ingenuo seguir pensando en el pasado: la idea de que Estados Unidos continúa siendo la fuerza dominante de la OEA, sencillamente, no es cierta. Por el contrario, sería deseable que los representantes de Estados Unidos ante la organización participaran con más intensidad y presentaran más iniciativas.

La OEA es una organización basada en los principios que forjaron la Unión Panamericana y que son la piedra angular del desarrollo del derecho internacional en las Américas. Como se ha podido resaltar a lo largo de este artículo, la noción de democracia ha estado permanentemente presente en las aspiraciones de los pueblos de la región y se ha visto reflejada en varios de sus principales instrumentos jurídicos. En particular, y luego de muchos altibajos, esta aspiración de los pueblos americanos fue consagrada como un derecho en la Carta Democrática Interamericana. 
Hoy, como se ha visto, ese derecho a la democracia enfrenta una serie de desafíos. La respuesta debe ser redoblar nuestros esfuerzos para fortalecer a la OEA y a la Carta Democrática. Sin embargo, para que ese proceso sea realmente exitoso, debemos empezarlo dentro de los propios países miembros - no en la organización-. La OEA es un reflejo de la voluntad política de sus Estados miembros, la cual, a su vez, debería también ser el reflejo de las aspiraciones de los pueblos de las Américas. 